\title{
DIAGNÓSTICO DA VULNERABILIDADE AMBIENTAL DA BACIA DO RIO TAQUARUÇU/MS
}

\author{
Angélica Estigarribia São Miguel ${ }^{1}$
}

Rafael Brugnolli Medeiros ${ }^{2}$

\section{Wallace de Oliveira ${ }^{3}$}

RESUMO: A vulnerabilidade ambiental diz respeito à fragilidade do ambiente em função de qualquer tipo de dano causado pela dinâmica ambiental por meio natural e/ou pela ação antrópica, sendo relacionada com a erosão do solo e assoreamento dos recursos hídricos. Desde modo, o presente estudo tem como objetivo realizar um diagnóstico sobre a vulnerabilidade ambiental na Bacia Hidrográfica do Rio Taquaruçu - MS, buscando analisar as potencialidades e fragilidades da bacia. A proposta utilizada no desenvolvimento do trabalho, apresentou como base a metodologia de Ross (1994) e Crepani et. al. (2001), baseada em 5 categorias hierárquicas de grau de vulnerabilidade, desde Muito Fraco até Muito Forte, utilizando-se como auxilio, as técnicas de sensoriamento remoto e geoprocessamento. A carta de vulnerabilidade ambiental foi realizada através da interpolação de dados como: pluviosidade, geologia, solos, declividade e uso e ocupação do solo. As classes de vulnerabilidade obtidas foram a categoria Fraca que se mostrou dominante na bacia, sendo áreas relacionadas com o extenso uso de pastagem para a criação de gado de corte e outros, a categoria Médio e Forte, que juntas apresentaram $29,5 \%$ da área total da bacia, como também foi encontrada em poucos locais, a categoria Muito Forte e não foi encontrada na bacia a classe Muito Fraca. Através desta pesquisa concluiu-se que em algumas áreas, os processos erosivos se encontram em estágio avançado, devido ao escoamento superficial

\footnotetext{
${ }_{1}^{1}$ Acadêmica de Geografia-Bacharelado - UFMS/CPTL - angelica.esm@hotmail.com;

${ }^{2}$ Acadêmico de Geografia-Bacharelado - UFMS/CPTL - rafael_bmedeiros@hotmail.com;

${ }^{3}$ Professor Adjunto da UFMS/CPTL - wallaceoliveira@hotmail.com;
} 
causado pela precipitação como também ao uso e ocupação da área, pois seu uso inadequado em certos locais eleva o grau de vulnerabilidade ambiental.

Palavras-chave: Bacia hidrográfica. Vulnerabilidade ambiental. Geoprocessamento. Processos erosivos.

\section{INTRODUÇÃO}

A pressão praticada pelo modelo econômico atual proporciona uma constante degradação ao ambiente natural como, desmatamento, empobrecimento dos solos, assoreamento, diminuição da biodiversidade e poluição de rios entre outros, por este motivo é necessário um estudo mais detalhado das bacias hidrográficas, resultando em grande aliado no desenvolvimento de técnicas apropriadas para controlar a deterioração ambiental.

Estes estudos são utilizados como formas de planejamento das bacias hidrográficas e gestão dos recursos naturais, visando o desaparecimento ou a diminuição dessa mudança na paisagem.

A unidade de estudo é a bacia hidrográfica, pois funciona como um sistema interativo, uma modificação em seus elementos leva a uma alteração no seu sistema. Charlton (2008 apud França Junior, 2010).

As bacias hidrográficas também têm grande importância na recuperação de áreas degradadas, até porque todos os danos ambientais que ocorrem estão situados nas bacias hidrográficas. Nesse sentido, é preciso conhecer a sua formação, constituição e dinâmica, para que as obras de recuperação não sejam apenas temporárias e sem grande eficácia (GUERRA, 2003).

Uma ferramenta utilizada neste processo de planejamento é o sensoriamento remoto, onde imagens de alta resolução são empregadas no mapeamento e monitoramento de todo o ambiente em questão.

Para a análise de como o solo vem sendo utilizado e ocupado e também outras análises ambientais, são necessárias imagens de satélite, que hoje em dia, devido a sua facilidade de obtenção, vêm se transformando em uma importante maneira de se verificar 
problemas e constatar todas as características da bacia, podendo assim elaborar diagnósticos quando é percebido o uso inapropriado dos recursos naturais.

A escolha do Rio Taquaruçu, localizado na divisa dos municípios de Brasilândia/MS e Santa Rita do Pardo/MS, se deu devido às alterações ambientais encontradas principalmente pela instalação de duas grandes empresas do ramo de cana de açúcar, a Companhia Brasileira de Açúcar e Álcool (CBAA) no município de Brasilândia/MS e do Grupo Brochmann Polis S/A instalada na fazenda Santa Vergínia no território de Santa Rita do Pardo/MS, sendo elas, empresas que exercem influência direta na mudança da paisagem na bacia e consequentemente elevam a vulnerabildiade do local, pois o cultivo de cana de açúcar exerce influência direta na fragilidade ambiental de uma bacia hidrográfica.

Para tanto, este estudo visou avaliar as fragilidades e potencialidades da área buscando um diagnóstico da vulnerabilidade ambiental, através da geração de dados de clima, geologia, solos, declividade e uso e ocupação do solo da bacia hidrográfica do Rio Taquaruçu/MS.

Este rio é afluente da margem direita do Rio Paraná e ocupa uma área de 2572,61 $\mathrm{km}^{2}$ entre as coordenadas geográficas: $52^{\circ} 57^{\prime} 12.19^{\prime \prime}$ e $52^{\circ} 04^{\prime} 32.11^{\prime \prime}$ W e $20^{\circ} 49^{\prime} 34.10^{\prime \prime}$ e $21^{\circ} 40^{\prime} 34.13^{\prime \prime}$ S. (Figura 1). 


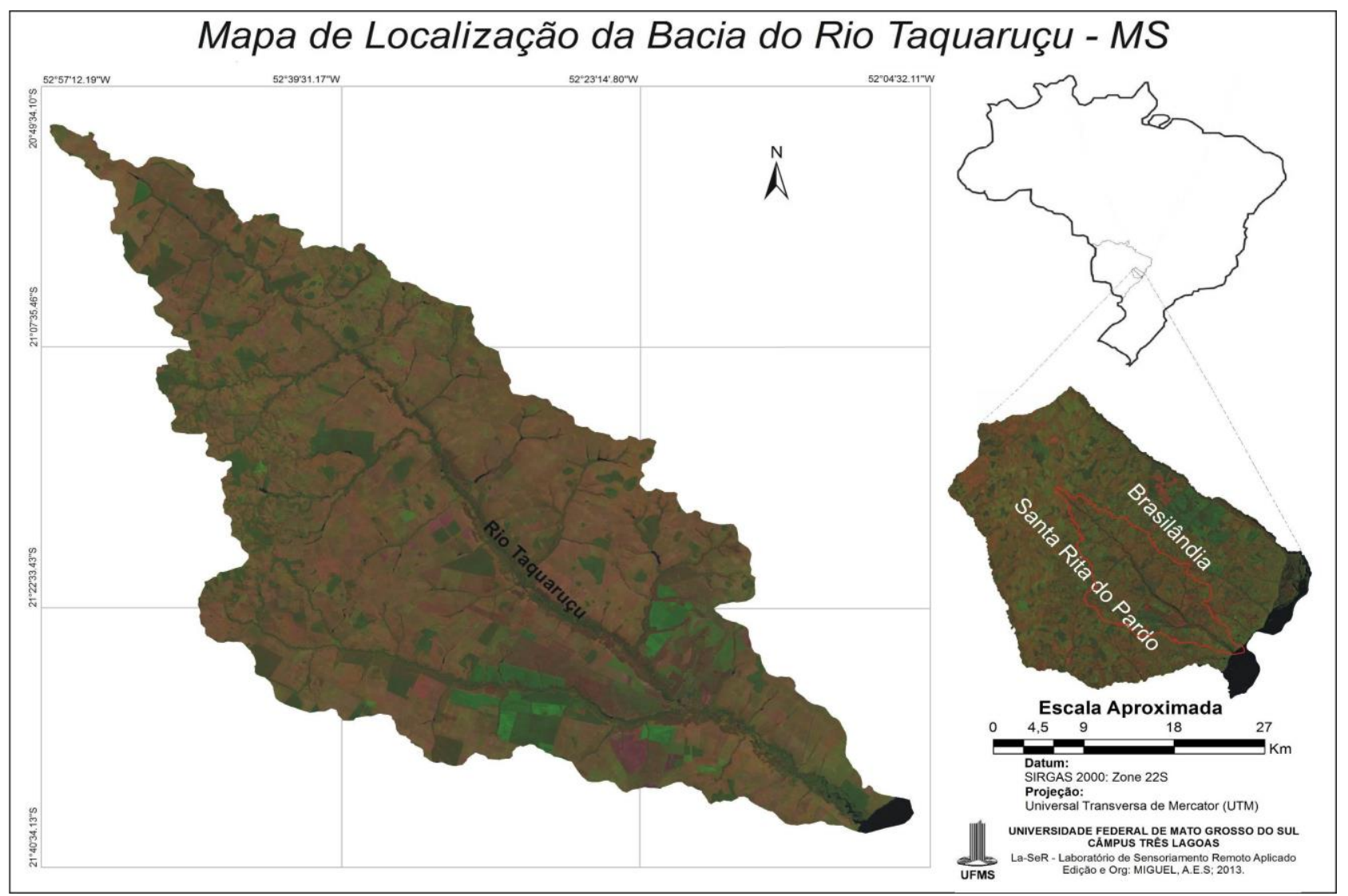

Figura 1: Mapa de localização da área de estudo.

\section{DESENVOLVIMENTO}

\subsection{METODOLOGIA}

$\mathrm{Na}$ elaboração da carta de vulnerabilidade ambiental, se utilizou de dados pluviométricos de 8 estações meteorológicas próximas da bacia do Rio Taquaruçu, sendo usado a média anual de cada estação.

Os dados climáticos são de extrema importância, pois de acordo com CREPANI et al., 2001, p.94.

"O clima controla os processos erosivos diretamente, através da precipitação pluviométrica e da temperatura de uma região, e também indiretamente através dos tipos de vegetação que poderão cobrir a paisagem" 
A média anual de cada estação foi disponibilizada no site da EMBRAPA CLIMA de Dourados/MS, sendo o banco de dados da Agência Nacional de Águas (ANA), representados na (Tabela 1).

Tabela 1: Estações meteorológicas, seus respectivos municípios, coordenadas geográficas e precipitação média anual.

\begin{tabular}{|c|c|c|c|}
\hline Estação & Município & $\begin{array}{l}\text { Coordenadas } \\
\text { Geográficas }\end{array}$ & $\begin{array}{l}\text { Média Anual } \\
\text { Precipitação } \\
\text { (mm) }\end{array}$ \\
\hline Estação Porto Velho & Brasilândia & $\begin{array}{l}\text { s } 21^{\circ} 01^{\prime} 00^{\prime \prime} \\
\text { w } 52^{\circ} 11^{\prime} 00^{\prime \prime}\end{array}$ & 1303,6 \\
\hline Estação Fazenda Mimosinho & Santa Rita do Pardo & $\begin{array}{l}\text { s } 21^{\circ} 06^{\prime} 00^{\prime \prime} \\
\text { w } 52^{\circ} 59^{\prime} 00^{\prime \prime}\end{array}$ & 1283,2 \\
\hline Estação Xavantina do Sul & Santa Rita do Pardo & $\begin{array}{l}\text { s } 21^{\circ} 17^{\prime} 42^{\prime \prime} \\
\text { w } 52^{\circ} 48^{\prime} 37^{\prime \prime}\end{array}$ & 1361,2 \\
\hline Estação Porto Uerê & Bataguassu & $\begin{array}{l}\text { s } 21^{\circ} 42^{\prime} 57^{\prime \prime} \\
\text { w } 52^{\circ} 26^{\prime} 14^{\prime \prime}\end{array}$ & 1304,4 \\
\hline Estação Três Lagoas (EFNOB) & Três Lagoas & $\begin{array}{l}\text { s } 20^{\circ} 48^{\prime} 00^{\prime \prime} \\
\text { w } 51^{\circ} 43^{\prime} 00^{\prime \prime}\end{array}$ & 831.5 \\
\hline Estação Água Clara & Ribas do Rio Pardo & $\begin{array}{l}\text { s } 20^{\circ} 26^{\prime} 42^{\prime \prime} \\
\text { w } 52^{\circ} 54^{\prime} 05^{\prime \prime}\end{array}$ & 1385,0 \\
\hline Estação Usina Mimoso & Ribas do Rio Pardo & $\begin{array}{l}\text { s } 20^{\circ} 40^{\prime} 35^{\prime \prime} \\
\text { w } 53^{\circ} 34^{\prime} 14^{\prime \prime}\end{array}$ & 1281,5 \\
\hline Estação Passagem Ribeirão Lontra & Ribas do Rio Pardo & $\begin{array}{l}\text { s } 21^{\circ} 24^{\prime} 30^{\prime \prime} \\
\text { w } 53^{\circ} 36^{\prime} 46^{\prime \prime}\end{array}$ & 1182,4 \\
\hline
\end{tabular}

Fonte: EMBRAPA CLIMA.

Org: MIGUEL, 2013.

A caracterização geológica da área de estudo foi elaborado com o auxílio do ArcGis $10^{\circledR}$, onde na extensão ArcMap 10, gerou-se o mapa geológico do estado do Mato Grosso do Sul na escala de 1:1.000.000, dados técnicos do Sistema Interativo de Suporte ao Licenciamento Ambiental (SISLA/IMASUL). A partir dos dados recortou a área da bacia, calculando-se a área em $\mathrm{km}^{2}$ que cada disposição geológica ocupa na bacia.

A carta de solos da área de estudo foi elaborado com o auxílio do $\operatorname{ArcGis}^{\circledR} 10$, no mesmo procedimento descrito no item anterior, utilizando os dados técnicos do SISLA/IMASUL, que foram adicionados ao $\operatorname{ArcGis}^{\circledR}$, onde o mesmo descreve a disposição dos solos pelas siglas, onde foi nomeado de acordo com a nova nomenclatura da EMBRAPA de 2006, finalizando assim a carta de solos. 
A declividade da bacia foi obtida através dos dados altimétricos da imagem SRTM, com o auxílio da ferramenta Spatial Analyst, em seguida a opção Surface e Slope, que oferece o declive em graus e/ou porcentagem, neste caso foi escolhida a porcentagem.

A elaboração da carta de declividade é uma ferramenta importante para a análise da qualidade ambiental, pois como Oliveira et al, (2007) afirma, o grau de declive do terreno exerce influência direta sobre a quantidade de perda de solo por erosão, pois, quanto maior seu gradiente, maior a intensidade de escoamento das águas sob o efeito da gravidade, sendo, menor o seu tempo disponível para a infiltração no solo.

Para a elaboração do uso e ocupação da terra foi feita uma interpretação da imagem de satélite ResourceSat 1 LISS-3, bandas 3,4 e 5 do ano de 2012 adquiridas gratuitamente no site do INPE - Instituto Nacional de Pesquisas Espaciais, para a delimitação da bacia utilizou a imagem de radar SRTM (Shuttle Radar Topography Mission) do ano de 2000.

As imagens foram importadas e georreferenciadas por meio de pontos de controle passíveis de identificação na imagem, sendo utilizada uma imagem ortorretificada pancromática da área como base pra registrar as novas imagens de satélite, trabalhados no SIG ArcGis ${ }^{\circledR}$ 10. Após o georreferenciamento o contraste foi executado no SIG Spring ${ }^{\circledR}$ 5.2.3 a fim de melhorar a qualidade da imagem, utilizando a opção equalizar histograma. A partir deste contraste foi salva a imagem sintética b3g4r5 das imagens Landsat TM e Resource Liss, classificando o uso e ocupação da terra, por meio de classificação supervisionada por regiões, onde foi utilizado o classificador Bhattacharya, cuja liminar de aceitação foi de 99,9\%.

Por fim a imagem classificada foi importada no ArcGis $^{\circledR} 10$, para corrigir os erros que no Spring ${ }^{\circledR}$ não foi possível, analisando cada região e mudando aquelas que apresentavam erros, alterando assim seu atributo de acordo com a realidade mostrada na imagem de satélite.

Após a geração destes dados, foi elaborada a carta de Vulnerabilidade Ambiental, para tanto, utilizou-se com algumas adaptações, as metodologias de Ross (1994) e Crepani et. al. (2001), sendo necessário o levantamento dos dados referentes à declividade, solos, geologia, clima, uso e ocupação do solo da bacia do Rio Taquaruçu para posteriormente ser dado pesos para cada característica física, (Quadro 1). 
Ross (1994) sistematizou uma hierarquia nominal de fragilidade, representado por classes: muito fraca (1), fraca (2), média (3), forte (4) e muito forte (5) de acordo com seu grau de vulnerabilidade.

Quadro 1:Pesos e Categorias de Vulnerabilidade Ambiental.
\begin{tabular}{|c|l|}
\hline Pesos & Categoria Hierárquica \\
\hline 1 & Muito Fraca \\
\hline 2 & Fraca \\
\hline 3 & Média \\
\hline 4 & Forte \\
\hline 5 & Muito Forte \\
\hline
\end{tabular}

Fonte: Adaptado de Ross (1994).

Org: MIGUEL, 2013.

\subsection{RESULTADOS}

Segundo Atlas Multirreferencial de Mato Grosso do Sul, (1990), o clima referente aos municípios de Brasilândia/MS e de Santa Rita do Pardo/MS é úmido a sub-úmido. A precipitação pluviométrica anual varia entre 1200 a 1750 mm anuais.

De acordo com a metodologia utilizada, percebe-se que os parâmetros referentes ao clima ocorrem homogeneamente em toda a área de estudo, sendo classificada como Peso 2, que são áreas de Fraca Vulnerabilidade, de acordo com CREPANI, et. al. (2001).

Segundo os dados obtidos pelo SISLA/IMASUL, a bacia hidrográfica do Rio Taquaruçu tem presença de Depósitos Aluvionares, Formação Santo Anastácio e Formação Caiuá.

Os Depósitos Aluvionares constituem os aluviões antigos e recentes encontrados na forma de faixas estreitas e alongadas com altitudes baixas (planícies aluviais e terraços aluviais), encontrados ao longo das calhas dos principais rios. Atualmente a maior parte dessas planícies encontra-se submersas pelos reservatórios das UHE Três 
Irmãos e Promissão, no Rio Tietê; bem como, no Rio Paraná, pela UHE Jupiá e futuramente, parcialmente recobertas pelo lago de Porto Primavera (CETEC, 1999, p.17).

A Formação Santo Anastácio sucede da Formação Caiuá um pacote de origem fluvial. Em sua parte inferior destaca-se um arenito cinza-pardo, vermelho-arroxeado ou creme, encontrando-se sempre envolto por uma película limonitizada. A granulação é predominantemente fina, esporadicamente média e grosseira, mostrando a presença de um cimento síltico e carbonático, que gradativamente vai aumentando; detectam-se sempre tênues intercalações síltico-argilosas tornando-se mais espessas para cima. Em sua camada superior apresenta arenito fino a médio, com predominância de terrenos arenosos em detrimento de constituintes pelíticos de coloração marrom-avermelhado ou pardacento, de seleção média com cimento silicoso e carbonático mais freqüente. (Atlas Multirreferencial de Mato Grosso do Sul, 1990).

A (Tabela 2) representa as áreas de ocorrência destas formações em $\left(\mathrm{km}^{2}\right)$ e porcentagens (\%).

Tabela 2: Disposição Geológica da Bacia do Rio Taquaruçu/MS.

\begin{tabular}{c|c|c|c}
\hline $\begin{array}{c}\text { Pesos de } \\
\text { Vulnerabilidade }\end{array}$ & Disposição Geológica & Área $\left.\mathbf{( k m}^{\mathbf{2}}\right)$ & Área (\%) \\
\hline 5 & Depósitos Aluvionares & 47,18 & 1,85 \\
\hline 2 & Formação Santo Anastácio & 513,41 & 19,95 \\
\hline 3 & Formação Caiuá & 2012,02 & 78,20 \\
\hline
\end{tabular}

Org: MIGUEL, A. E. S.; (2013).

Nota-se que na grande parte bacia é predominante a Formação Caiuá com uma área de $2012,02 \mathrm{~km}^{2}$ ou $78,20 \%$ da área total da bacia, sendo essa, uma formação mais antiga que a Formação Santo Anastácio, que abrange uma área de $513,41 \mathrm{~km}^{2}$ ou $19,65 \%$ do total. Já a formação mais recente, que é predominantemente composta por arenitos e cascalho, chamada de Depósitos Aluvionares, compreende uma área de $47,18 \mathrm{~km}^{2}$ ou $1,85 \%$, sendo predominante nas áreas próximas aos cursos d'água principais no baixo curso e nas margens do Rio Paraná.

Foram constatados vários tipos de solos na bacia do Rio Taquaruçu, como demonstrado na (Tabela 3), predominante na bacia, o Latossolo vermelho, que são solos constituídos de material mineral, sendo solos em avanço estágio de intemperização, bem evoluídos, normalmente profundos e variam de fortemente a bem drenados. Sendo 
encontrados geralmente em regiões planas ou suaves onduladas. Os solos Argissolo Vermelho/Amarelo e Argissolo Vermelho são solos minerais, que tem como características diferenciais a presença do horizonte B textural de argila de atividade baixa ou alta conjugada por bases baixa ou caráter alitico. Planossolos, solos típicos de relevo plano e áreas rebaixadas, são solos minerais imperfeitamente ou mal drenados, com horizonte superficial ou subperficial eluvial de textura mais leve. Neossolo são solos de material mineral ou orgânico pouco espesso, que apresenta alterações expressivas em relação ao material originário devido à baixa intensidade de atuação dos processos pedogenéticos, sejam em razão as características inerentes ao próprio material de origem, são mais resistentes ao intemperismo (EMBRAPA, 2006).

Associação Complexa, unidade composta por vários tipos de solos, onde não é possível identificar qual deles é o dominante, sendo difícil a separação mesmo em estudo em escalas maiores, no caso da bacia do Rio Taquaruçu foi identificado o AC2: Planossolo + Gleissolos + Neossolos + Organossolos, ocorrendo em área marginal ao Rio Paraná (SEMAC/SUPLAN, 2011).

A (Tabela 3) mostra a disposição dos solos da bacia em porcentagem (\%) e em $\mathrm{km}^{2}$.

Tabela 3: Solos da Bacia do Rio Taquaruçu/MS.

\begin{tabular}{c|l|c|c}
\hline $\begin{array}{c}\text { Pesos de } \\
\text { Vulnerabilidade }\end{array}$ & \multicolumn{1}{|c|}{ Solos } & Área $\mathbf{( k m}^{\mathbf{2})}$ & Área (\%) \\
\hline 1 & Latossolo Vermelho & 1971,28 & 76,62 \\
\hline 3 & Planossolo & 164,31 & 6,38 \\
\hline 4 & Argissolo Vermelho & 186,36 & 7,24 \\
\hline 5 & Argissolo Vermelho/Amarelo & 238,46 & 9,26 \\
\hline 5 & Neossolo Quartzarenico & 0,08 & 0,03 \\
\hline
\end{tabular}

Org: MIGUEL, A. E. S.; (2013).

A carta de declividade foi elaborada a partir da interpolação das curvas de nível com equidistância de 40 metros, a partir da imagem SRTM e os dados obtidos e totais da área estão na (Tabela 4). As classes de declividades tiveram como base a proposta por Ross (1994). Deste modo identificou cinco classes de declividade: <3\%, 3-6\%, 6-12\% e $12-20 \%$ e $20-30 \%$. 
Tabela 4: Classes de declividade na bacia do Rio Taquaruçu em área $\left(\mathrm{km}^{2}\right)$ e porcentagem (\%).

\begin{tabular}{c|c|c|c}
\hline $\begin{array}{c}\text { Pesos de } \\
\text { Vulnerabilidade }\end{array}$ & $\begin{array}{c}\text { Classes de Declive } \\
(\%)\end{array}$ & Área $\left(\mathbf{k m}^{2}\right)$ & Área (\%) \\
\hline 1 & 0 a 6 & 2401,67 & 93,35 \\
\hline 2 & 6 a 12 & 169,25 & 6,58 \\
\hline 3 & 12 a 20 & 1,61 & 0,07 \\
\hline 4 & 20 a 30 & 0,08 & 0,00 \\
\hline \multicolumn{2}{r}{} \\
\hline
\end{tabular}

Org: MIGUEL, 2013.

Comparando com os dados da (Tabela 4), fica claro o predominio dos baixos graus de inclinação do terreno, (0 a $6 \%$ ) somando $93,35 \%$ do total da área estudada, percebendo-se que na bacia predomina um relevo plano sem muitas alterações bruscas de altitude. A segunda classe que mais se apresenta na bacia, é de $6-12 \%$ de declividade, abrangendo uma área relativamente pequena de acordo com o tamanho da bacia, apenas $169,25 \mathrm{~km}^{2}$, ou seja, $6,58 \%$, em grande parte no médio alto curso da bacia.

A classe nomeada como média, de 12 a $20 \%$ de declive, se apresentou em áreas pequenas, representando apenas $1,61 \mathrm{~km}^{2}$, que segundo a classificação de Lepsch et al. (2002) são áreas com predomínio à problemas com erosão, entretanto, impróprias para culturas anuais e indicadas para culturas perenes, para proporcionar uma proteção maior ao solo.

Por fim a classe que menos se apresentou na bacia, foi a classe de 20 a $30 \%$ ou Forte, que foi notada apenas em uma pequena área de $0,08 \mathrm{~km}^{2}$ no baixo curso do Rio Taquaruçu próxima à foz no Rio Paraná.

$\mathrm{Na}$ interpretação de imagens de satélites diversos fatores devem ser levados em consideração como, por exemplo, o nível de experiência do analista, as características das bandas utilizadas pelo satélite utilizado no imageamento e principalmente, o conhecimento da área de estudo. Na verdade, quanto maior é o conhecimento sobre a área de estudo, maior é a qualidade de informações que podem obter (FLOREZANO, 2007, p.43).

A realização da saída de campo é um processo fundamental para a finalização da carta do uso e ocupação, pois nela foi possível tirar todas as dúvidas referentes à 
classificação da imagem, finalizando assim a carta temática referente à bacia do Rio Taquaruçu.

$\mathrm{Na}$ (Tabela 5) apresenta os dados gerados pelo $\operatorname{ArcGis}^{\circledR} 10$, em $\left(\mathrm{km}^{2}\right)$ e porcentagens (\%) do uso e ocupação do solo no ano de 2012.

Tabela 5: Uso e Ocupação do solo no ano de 2012.

\begin{tabular}{c|c|c|c}
\hline $\begin{array}{c}\text { Pesos de } \\
\text { Vulnerabilidade }\end{array}$ & Classes & Área $\left.\mathbf{( k m}^{\mathbf{2}}\right)$ & Área (\%) \\
\hline 3 & Florestal & 513,46 & 19,95 \\
\hline 3 & Pastagem & 1373,87 & 53,40 \\
\hline 4 & Silvicultura & 58,73 & 2,28 \\
\hline 4 & Lavoura Temporária & 323,87 & 12,58 \\
\hline 5 & Solo úmido & 127,35 & 4,95 \\
\hline 5 & Solo nu & 129,92 & 5,05 \\
\hline & Água & 45,41 & 1,79 \\
\hline
\end{tabular}

Fonte: RESOURCE SAT 1 LISS3, 2012. Org: MIGUEL, 2013.

Analisando a (Tabela 5), a classe Florestal representava uma área 19,95\% do total, essa classe florestal é característica na região em pequenas áreas ao longo das fazendas, mas parte de suas áreas foram encontradas próximas aos cursos d'água, nas matas ciliares (Figura 2). A Pastagem se mostrou predominante na bacia do Rio Taquaruçu/MS, com 53,40\% de toda a área da bacia (Figura 3).

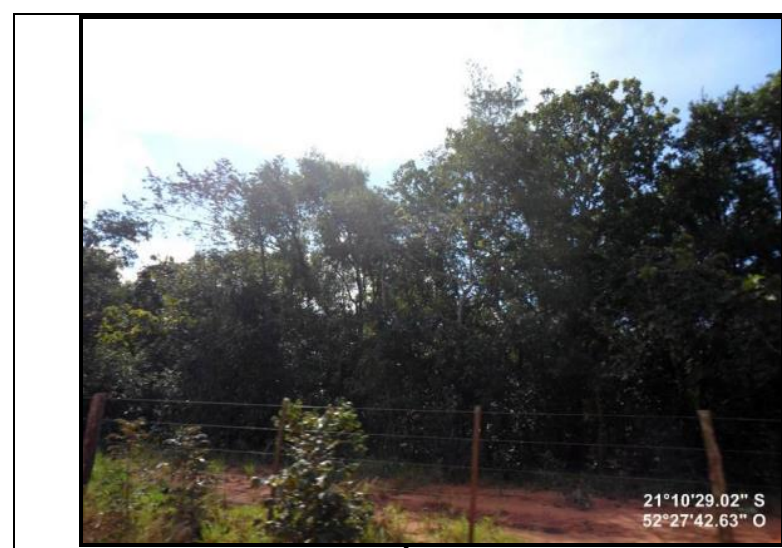

Figura 2: Área Florestal.

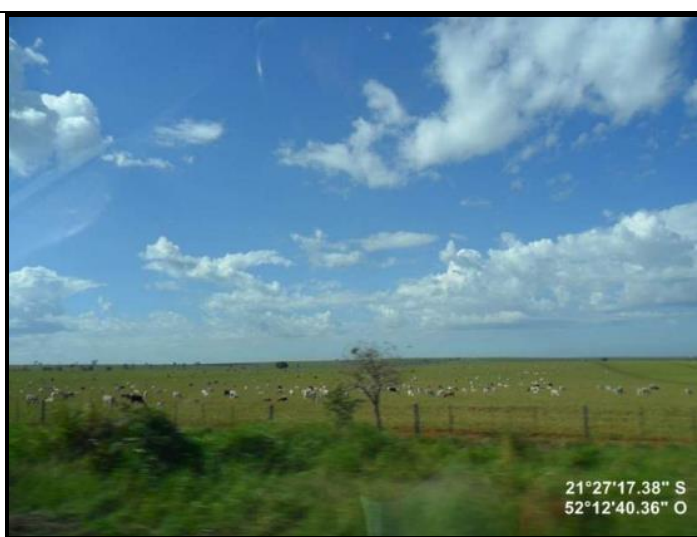

Figura 3: Pastagem destinada à criação de Gado de Corte.

Fonte: MIGUEL, 2013.

A classe Silvicultura em 2012 representava uma área de 2,28\% da bacia, já a Lavoura Temporária (cana de açúcar) passou pra 12,58\% no ano de 2012, em sua grande 
parte, no médio curso do Rio Taquaruçu, em áreas próximas das empresas de cultivo de cana de açúcar, (Figura 4 e 5).

O solo úmido em 2012 representou uma área de 4,95\% da área e o solo nu ocupou $5,05 \%$. Já a classe de água representou uma área de 1,79\%

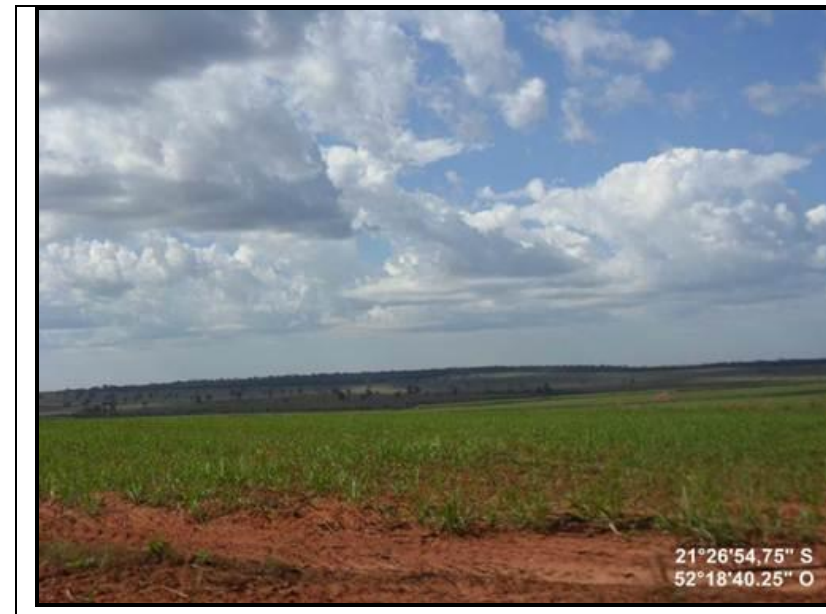

Figura 4: Inicio do plantio de Cana de açúcar.

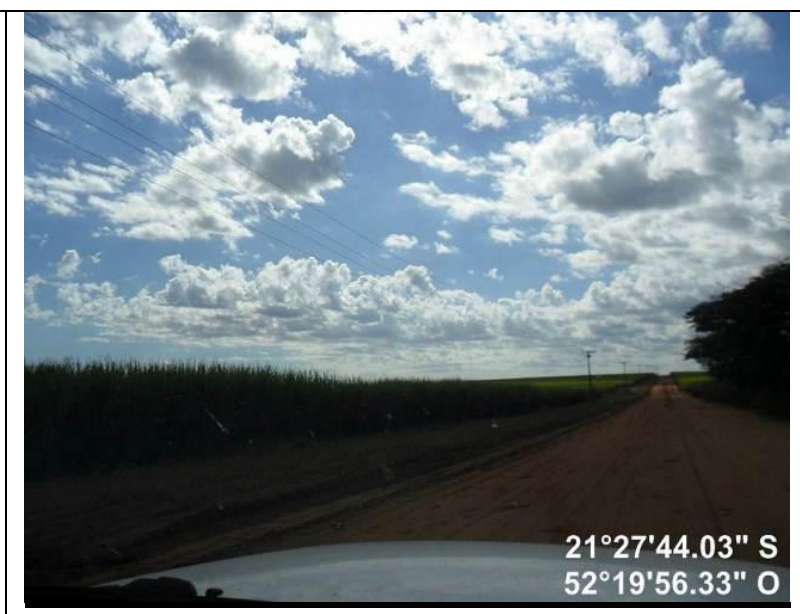

Figura 5: Plantio de cana de açúcar na região.

Fonte: MIGUEL, 2013.

Por fim, após a análise de todos estes fatores que interferem na vulnerabilidade ambiental, foi gerada a carta de vulnerabilidade, pois permite um diagnóstico sobre as fragilidades de uma bacia hidrográfica perante as diversas pressões exercidas sobre a mesma. Essa informação é favorável ao planejamento ambiental, pois possibilita identificar locais onde essas pressões exercidas têm potencial para causar uma maior degradação ambiental.

Os estudos relativos à fragilidade dos ambientes são de extrema importância ao Planejamento Ambiental, onde a identificação dos ambientes naturais e suas fragilidades potenciais e emergentes proporcionam uma melhor definição das diretrizes e ações a serem implementadas no espaço físico-territorial, servindo de base para o zoneamento e fornecendo subsídios à gestão do território (Spörl e Ross, 2004).

As unidades mapeadas na carta de Vulnerabilidade Ambiental (Figura 6) e descritas na (Tabela 6). 
Tabela 6: Vulnerabilidade Ambiental e suas respectivas características encontradas na bacia em $\left(\mathrm{km}^{2}\right)$ e (\%).

\begin{tabular}{c|c|c|c}
\hline Pesos & Categoria Hierárquica & $\begin{array}{c}\text { Área } \\
\left.\mathbf{( k m}^{2}\right)\end{array}$ & $\begin{array}{c}\text { Área } \\
\mathbf{( \% )}\end{array}$ \\
\hline 1 & Muito Fraca & 0,00 & 0,00 \\
\hline 2 & Fraca & 1811,76 & 70,42 \\
\hline 3 & Média & 551,28 & 21,43 \\
\hline 4 & Forte & 207,64 & 8,07 \\
\hline 5 & Muito Forte & 1,93 & 0,08 \\
\hline
\end{tabular}

Org: MIGUEL (2013).

Na bacia do Rio Taquaruçu não obteve a categoria de vulnerabilidade Muito Fraca, apesar de ter variáveis com essa classificação, com a interpolação dos dados, se enquadraram em outras classes.

A categoria fraca se mostrou dominante na bacia, representando $70,42 \%$ do total da área, se tornando presentes em áreas florestais e de pastagem, como também pela pluviosidade se enquadrar nesta classe. A vulnerabilidade à erosão nesta classe é caracterizada pela fraca erosão laminar, sem evidência erosiva, com infiltração das águas, ou moderada, com ligeiras evidências de sinais incipientes de erosão laminar por escoamento difuso ou semiconcentrado, (MEDINA, et. al, 2000).

A categoria de vulnerabilidade média representa $21,43 \%$ da área da bacia, sendo grande parte do plantio de Lavoura Temporária e Silvicultura se encontrou nessa classe de vulnerabilidade. Esta classe de vulnerabilidade relaciona-se a uma instabilidade morfodinâmica caracterizada por erosão laminar fraca a média responsável pela remoção parcial dos horizontes superficiais dos solos e pela existência de sulcos erosivos localizados pelo escoamento semiconcentrado, (MEDINA, et. al, 2000).

A classe de vulnerabilidade forte se apresentou em uma área de $207,64 \mathrm{~km}^{2}$ ou 8,07\% da área total da bacia, sendo encontrados em áreas de solo úmido e áreas distribuídas pela bacia, sendo que a lavoura temporária se enquadrou nesta classe, mas devido a interpolação com as outras variáveis necessárias para a elaboração da carta de vulnerabilidade, foi classificada como áreas de vulnerabilidade média. Estes terrenos são bastante suscetíveis à erosão, a vulnerabilidade forte evidencia-se pela remoção parcial 
dos horizontes superficiais dos solos, presença localizada de sulcos, ravinas e terracetes de pisoteio, principalmente quando o pastoreio é intenso. (MEDINA, et. al, 2000).

A categoria muito forte foi encontrada próxima a foz do Rio Taquaruçu, mas não foi possível identificar na carta (Figura 6), por se tratar de uma área de apenas 0,08\%. Devido ao seu declive, solos e geologia se enquadraram em uma classe de fragilidade muito forte. Corresponde às áreas com declividades acentuadas nos bordos dos tabuleiros costeiros, ao longo das vertentes dos vales mais profundamente dissecados e nas cabeceiras de drenagem (Ocorrem solos com horizontes superficiais degradados, grandes concentrações de terracetes de pisoteio, sulcos erosivos, ravinas e cicatrizes de deslizamento, (MEDINA, et. al, 2000).

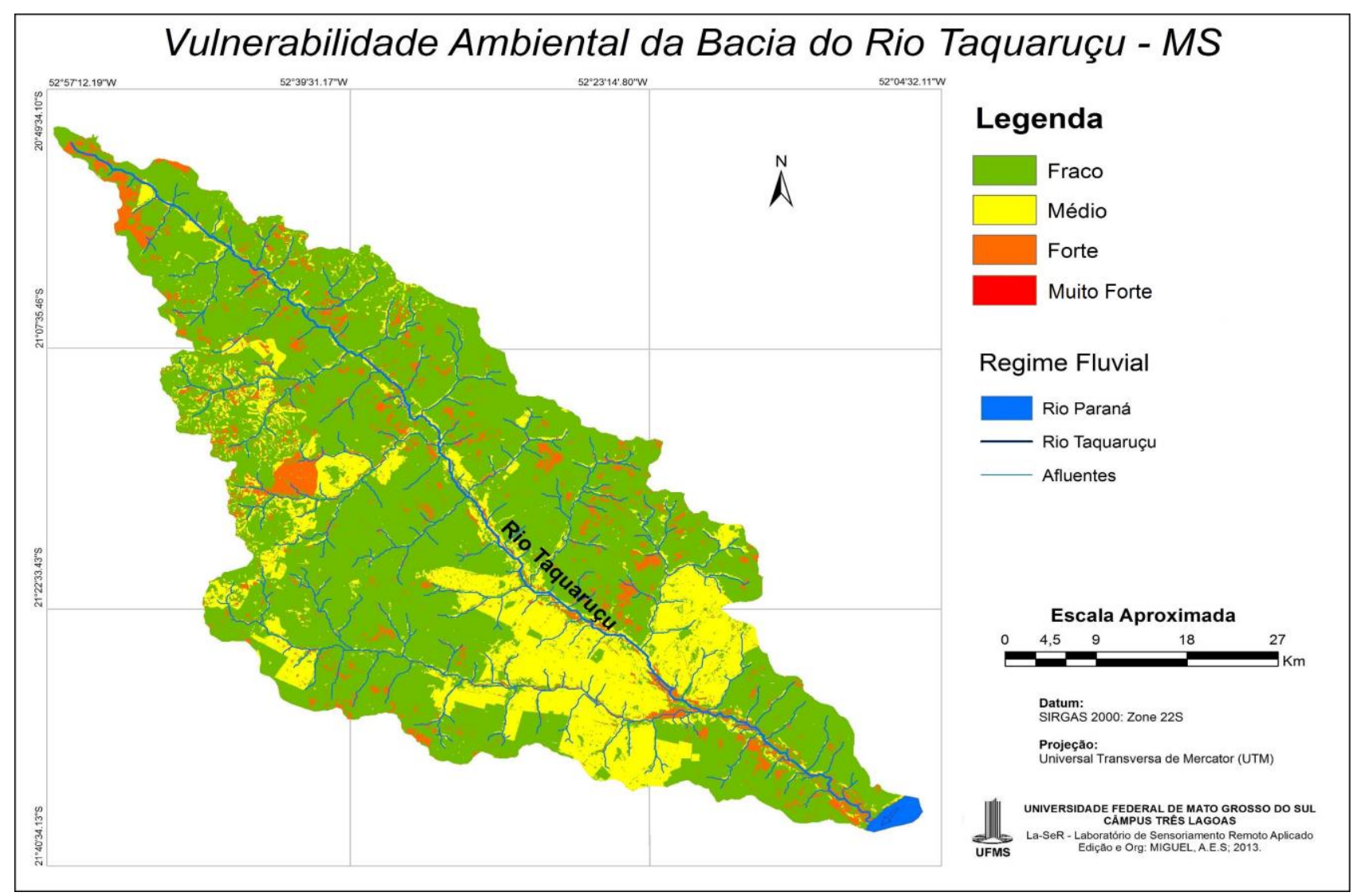

Figura 6: Carta de vulnerabilidade ambiental da bacia hidrográfica do Rio Taquaruçu/MS.

Percebe-se que a maioria das pastagens encontradas na bacia, tem como característica a criação de gado de corte, que é um diferencial na questão da vulnerabilidade, pois o pisoteio do gado interfere na perda de solo e aumento do risco de erosões. 


\section{Then Fórum Ambiental \\ da Alta Paulista

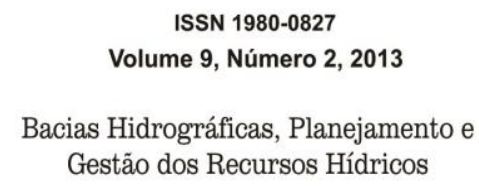

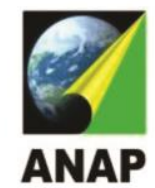

Outro fator que altera significativamente a vulnerabilidade ambiental é a prática e cultivo, segundo Morgan (1984 apud GUERRA, 1998), as práticas agrícolas reduzem à cobertura vegetal dos solos, deixando, certos tipos de solos, mais sensíveis a erosão, pois o impacto da chuva e maior quando ha menor resistência dos agregados, consequência da diminuição da matéria orgânica no solo.

\section{CONCLUSÃO}

Conclui-se que a bacia hidrográfica, por ser uma área extremamente dinâmica, necessita de um diagnostico de todas as características do local, esse diagnóstico culmina com descoberta de áreas vulneráveis e potencialmente propensas a erosões, por este motivo analisar e descobrir a vulnerabilidade ambiental de uma determinada área é importante, pois se percebe que as unidades possuem propriedades comuns, sendo que o estado de cada unidade é controlado, condicionado ou dependente do estado das demais unidades. Acrescenta-se ainda que "os sistemas não atuam de modo isolado, mas funcionam dentro de um ambiente e fazem parte de um conjunto maior" (MMA, 2001.14).

Para tanto, as técnicas de sensoriamento remoto e geoprocessamento possibiltou a geração das cartas utilizadas para a elaboração deste trabalho, se tornando úteis na obtenção e geração de todos os dados utilizados, através dos softwaeres ArcGis $10 \mathrm{e}$ Spring 5.2.3 em um Sistema de Informação Geográfica proporcionou um resultado satisfatório.

$\mathrm{Na}$ bacia se mostraram notáveis os processos erosivos, que em alguns locais se encontram em estágios avançados, devido ao escoamento superficial causado pela precipitação que aumenta o grau de vulnerabilidade ambiental e consequentemente esse solo é levado até áreas mais baixas da bacia que são os fundos de vale e os recursos hídricos, alterando assim a dinâmica do ambiente.

De forma geral, a bacia obteve um grau de vulnerabilidade fraca elevada, totalizando $1811,76 \%$ de toda a área da bacia, o que mostra que não é uma área extremamente vulnerável, mas como também é necessário este diagnostico, para apontar as fragilidade e potencialidades encontradas, para futuramente auxiliar em possíveis ações e novos estudos que ofereçam um melhor ordenamento à bacia, visando o aumento da qualidade de seus recursos naturais. 


\section{REFERÊNCIAS}

ATLAS MULTIRREFERENCIAL. Governo do Estado de Mato Grosso do Sul - SEPLAN. IBGE, 1990.

CETEC. Centro Tecnológico de Fundação Paulista de Tecnologia e Educação. CBH-BT Comitê da Bacia Hidrográfica do Baixo Tietê. Situação dos Recursos Hídricos do Baixo Tietê - UGRHI 19. Minuta Preliminar do Relatório Técnico Final. Diretor - CTEC: Wiltevar Verati. Lins, ago. 1999.

CREPANI, E.; MEDEIROS, J.S. de; HERNANDEZ FILHO, P.; FLORENZANO, T.G.; DUARTE, V.; BARBOSA C.C.F. - Sensoriamento Remoto e Geoprocessamento Aplicados ao Zoneamento Ecológico Econômico e ao Ordenamento Territorial. São José dos Campos, Junho de 2001 (INPE 8454-RPQ/722).

EMBRAPA. Centro Nacional de Pesquisa de Solos. Sistema brasileiro de classificação de solos. 2.ed. Rio de Janeiro, 2006. 306p.

EMBRAPA. Clima MS. Disponível em:

<http://www.cpao.embrapa.br/clima/index.php?pg=chuvams> Acesso em: 11 de Jun. 2013.

ESRI. Arc GIS: the complete Geographic Information System. Disponível em: http://www.esri.com/software/arcgis/index.html. Acesso em: 05 de fev; 2013.

FLOREZANO, T. Iniciação em Sensoriamento Remoto - São Paulo: Oficina do Texto, 2007.

FRANÇA JUNIOR, P. Análise do uso e ocupação da bacia do córrego Pinhalzinho II utilizando geoindicadores, Umuarama-PR, 1970-2009 -- Maringá, 2010. p.103.

GUERRA, A. J. T. Encostas e a questão ambiental. In: CUNHA,S. B.; GUERRA, A. J. T. (Org.). Questão ambiental: diferentes abordagens. Rio de Janeiro: Bertrand Brasil, 2003. p.191-218.

GUERRA, A. J. T. Processos Erosivos nas Encostas. In: GUERRA, A.J.T. e CUNHA, S.B. Geomorfologia: uma atualização de base e conceitos. Bertrand Brasil.3eed. Rio de Janeiro, 1998.p. 149-209.

IBGE. Instituto Brasileiro de Geografia e Estatística. Manual de uso e ocupação da terra. Manuais Técnicos em Geociências. Brasil número 7. Brasília, 2006. 91 p.

LEPSCH, I. F. Formação e Conservação dos solos. São Paulo: Ofícina de Textos, 2002,178p. 
MEDINA, A. I. M (Org). Projeto Porto Seguro - Santa Cruz Cabrális: Geomorfologia, Avaliação da Vulnerabilidade à Erosão e Diagnóstico Geoambiental. Salvador: CPRM/SUREG/SA, 2000. 87p.

MMA. Programa Zoneamento Ecológico-Econômico: diretrizes metodológicas para - zoneamento ecológico-econômico do Brasil. Ministério do Meio Ambiente Secretaria de Políticas para o Desenvolvimento Sustentável. Brasília - DF, 2001.

OLIVEIRA, A.M.M.; PINTO, S.A.F.; LOMBARDI NETO, F. Caracterização de indicadores da erosão do solo em bacias hidrográficas com o suporte de geotecnologias e modelo predictivo. Estudos Geográficos, Rio Claro, v.5, p.63-86, 2007

ROSS, J. L. S. Análise Empírica da Fragilidade dos Ambientes Naturais e Antropizados. Revista do Departamento de Geografia. São Paulo: FFLCH-USP, n8, 1994.

SEMAC/SUPLAN - Secretaria de Estado de Meio Ambiente, do Planejamento, da Ciência e Tecnologia - Disponível em: <http://www.semac.ms.gov.br/> Acesso em: 14 de Abr. 2013.

SISLA/IMASUL - Sistema Interativo de Suporte ao Licenciamento Ambiental Disponível em: <sisla.imasul.ms.gov.br> Acesso em: 22 de Maio. 2013.

SPÖRL, C.; ROSS, J. L. S. Análise comparativa da fragilidade ambiental com aplicação de três modelos. São Paulo, Revista Geousp - Espaço e Tempo, №15, pp. 39-49, 2004. 